\title{
AN INSTRUMENT FOR THE CONTROLLED TRIMMING OF PLASTIC SPECIMEN BLOCKS FOR LIGHT AND ELECTRON MICROSCOPY
}

\author{
K. Mendgen and R. E. Gold, Institute for Plant Pathology and Plant Protection, \\ University of Göltingen, D-3400 Göltingen, and Chair of Phylopathology, Faculty of Biology, \\ University of Constance, D-7750 Conslance, Federal Republic of Germany
}

\begin{abstract}
Aasract. A device for the controlled trimming of plastic specimen blocks for light and electron microscopy is described. Many advantages of previously reported instruments together with 1) a rack and pinion control of knife movement, and 2) a control of rotation of the specimen block at $90^{\circ}$, $180^{\circ}, 270^{\circ}$, or $360^{\circ}$ are incorporated. In conjunction with an ocular micrometer, the device allows accurate removal of thin slices during trimming.
\end{abstract}

Several devices and techniques have been described which aid in the trimming of plastic embedded specimen blocks to form "pyramids" (= truncated pyramids) before they are mounted into the microtome (Boyde 1960, Butler 1974, Danon 1961, Guglielmotti 1976, Schneider and Sasaki 1976, Sjöstrand 1967). Gorycki (1978) described a "rectangular trimming block" which, in conjunction with a small mirror mounted on the knife holder of the ultramicrotome, squarely retrimmed the block face of a preformed truncated pyramid. Similarly, Sjöstrand's device (Sjöstrand 1967) is a trimming aid intended only for the final trimming and retrimming of tissue blocks. Using such instruments, block faces with parallel edge alignment can be, with an experienced hand, precisely produced.

In comparison to hand trimmers which simply employ knife guides (Butler 1974, Danon 1961, Guglielmotti 1976, Schneider and Sasaki 1976), the trimmer described in the present communication allows more accurate, mechanically-guided trimming from untrimmed plastic specimen blocks. The device, in conjunction with an ultramicrotome and a stereomicroscope, facilitates rapid, preferential shaping of the block face to leave only the area of interest at the tip in the plane of section. Furthermore, compared with the mechanically-guided commercially available instruments (i.e. LKB, Reichert) it was considerably less expensive to construct.

The device permits accurate movement of the knife by use of a rack and pinion on the knife-moving assembly. The knife is set at a cutting angle of $45^{\circ}$ to produce untruncated pyramids with an apex of $90^{\circ}$. Horizontal movement of the mounted specimen is also mechanically possible in two directions at right angles to each other. This, in conjunction with the ocular micrometer of the microscope, enables the orientation; thickness and exact location of the slices of plastic removed to be precisely controlled. Rotation of the specimen allows parallel edge alignment which is necessary for clean, long ribbons. If desired, slight adjustments during shaping of the specimen block allows trapezoidal block faces to be formed (Fig. 3f). This instrument has been used successfully in our laboratory for over a year with both Spurr's and Epon-Araldite epoxy resins as well as with paraffin embedments. If

Present address of both authors: Lehrstuhl für Phytopathologie der Universität Konstanz, D-7750 Konstanz, Federal Republic of Germany. 
necessary, the trimmer could be easily modified to be used with other brands of equipment.

\section{DESCRIPTION}

All components of the trimmer were machined in the metal workshop of the Institute für Pflanzenpathologie und Pflanzenschutz der Universität Göttingen according to the size and dimensions shown in Figures 1 and 2. However, all mechanical components and materials necessary to build such a trimmer are also commercially available. In the following description, letters refer to the technical diagram (Fig. 1).

The supporting structure $(B)$ for the horizontal control unit $\left(\mathrm{C}_{1}, \mathrm{C}_{2}\right)$ and the adjustable support (S) for the knife arm are both attached to the flat, disc-shaped base plate (A). The base plate can be securely fastened to a dissecting microscope with the mounting pins (m). The stem (st) of the horizontal control unit is inserted into the supporting structure which contains 2 sets of housed ball-bearings which allow smooth, play-free rotation of the firmly seated horizontal control unit. Click stops at $90^{\circ}, 180^{\circ}, 270^{\circ}$, or $360^{\circ}$ for the horizontal control unit are provided by a spring pin and corresponding grooves in the upper portion of the control unit's stem (arrow). The horizontal control unit is composed of two transverse slides which are fastened at right angles to each other and allow full horizontal adjustment of the specimen block. Fastened to the top of the horizontal control unit is a

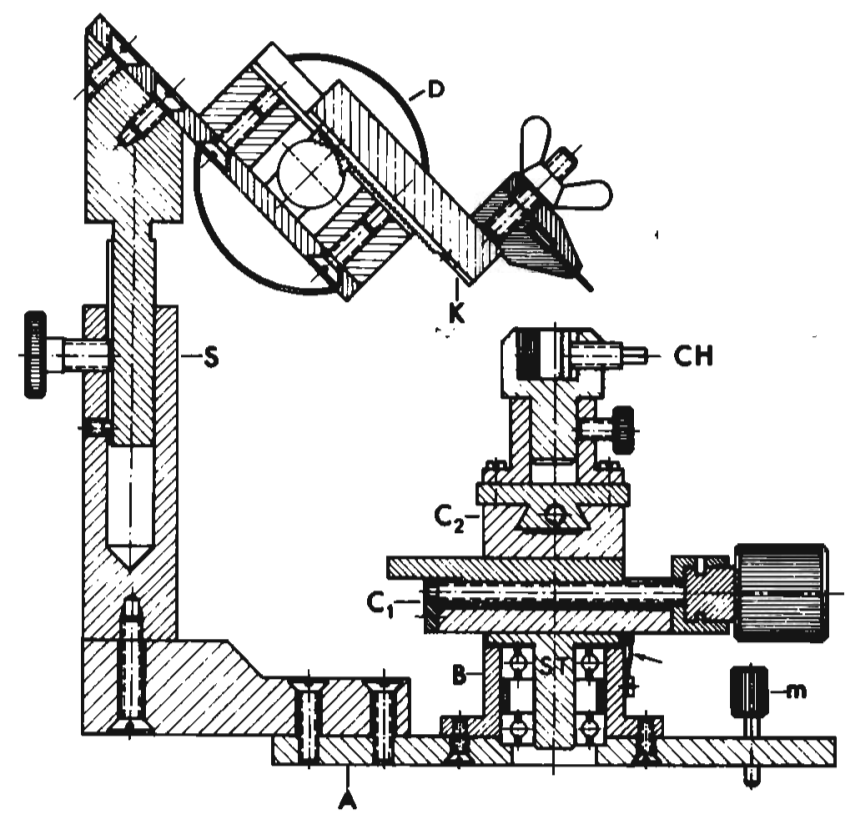

FIG. 1. Sectional view of the trimming apparatus. $A=$ base plate, $B=$ trimmer base, $\mathbf{C}_{1}+\mathrm{C}_{2}=$ horizontal control units, $\mathrm{CH}=$ microtome chuck, $\mathrm{K}=$ knife guide, $\mathrm{m}=$ mounting pin (only one shown), $\mathrm{S}=$ knife arm support, $\mathrm{ST}=$ stem, $\mathrm{D}=$ Drive wheel. $\times 0.5$. 


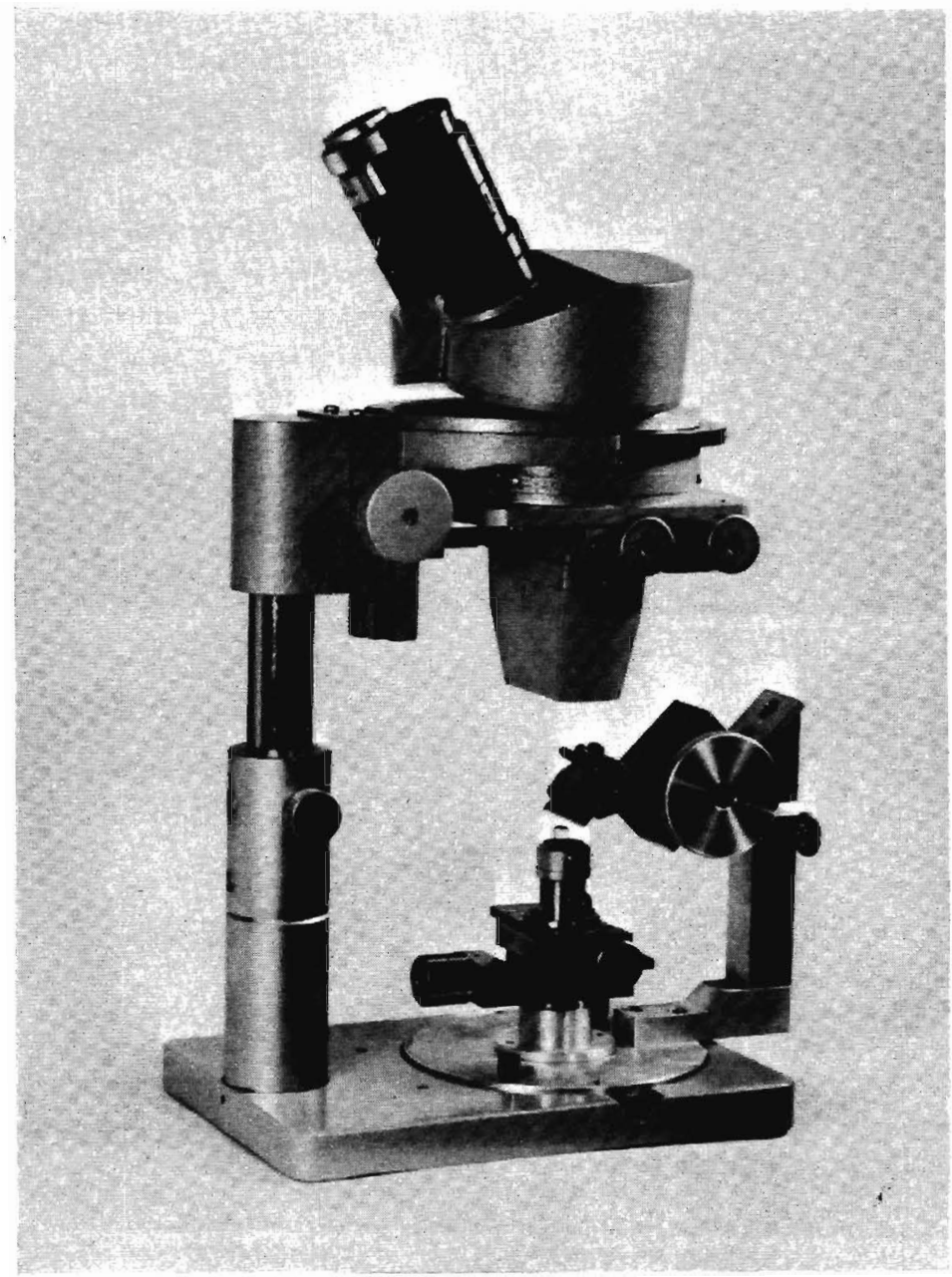

Fig. 2. Side view of the trimmer mounted on the base of a Leitz dissecting microscope.

chuck. The microtome chuck $(\mathrm{CH})$, containing either flat or cylindrical specimen blocks, is mounted in the trimmer's chuck.

The stem of the adjustable support $(\mathrm{S})$ for the knife arm is grooved to allow wander-free vertical movement during adjustment of the knife to the height of the specimen block. Positive control of the movement of the knife is provided by the rack and pinion gear between the drive wheel (D) and the knife guide (K). The razor blade is held between two jaws by a bolt with a wing nut and can be adjusted laterally to utilize its full cutting edge.

\section{USE}

The trimming procedure is as follows: A flat or cylindrical specimen block is mounted in a microtome chuck. The first step is to trim the top surface of the block flat with a microtome until the embedded tissue is exposed or nearly so. The 

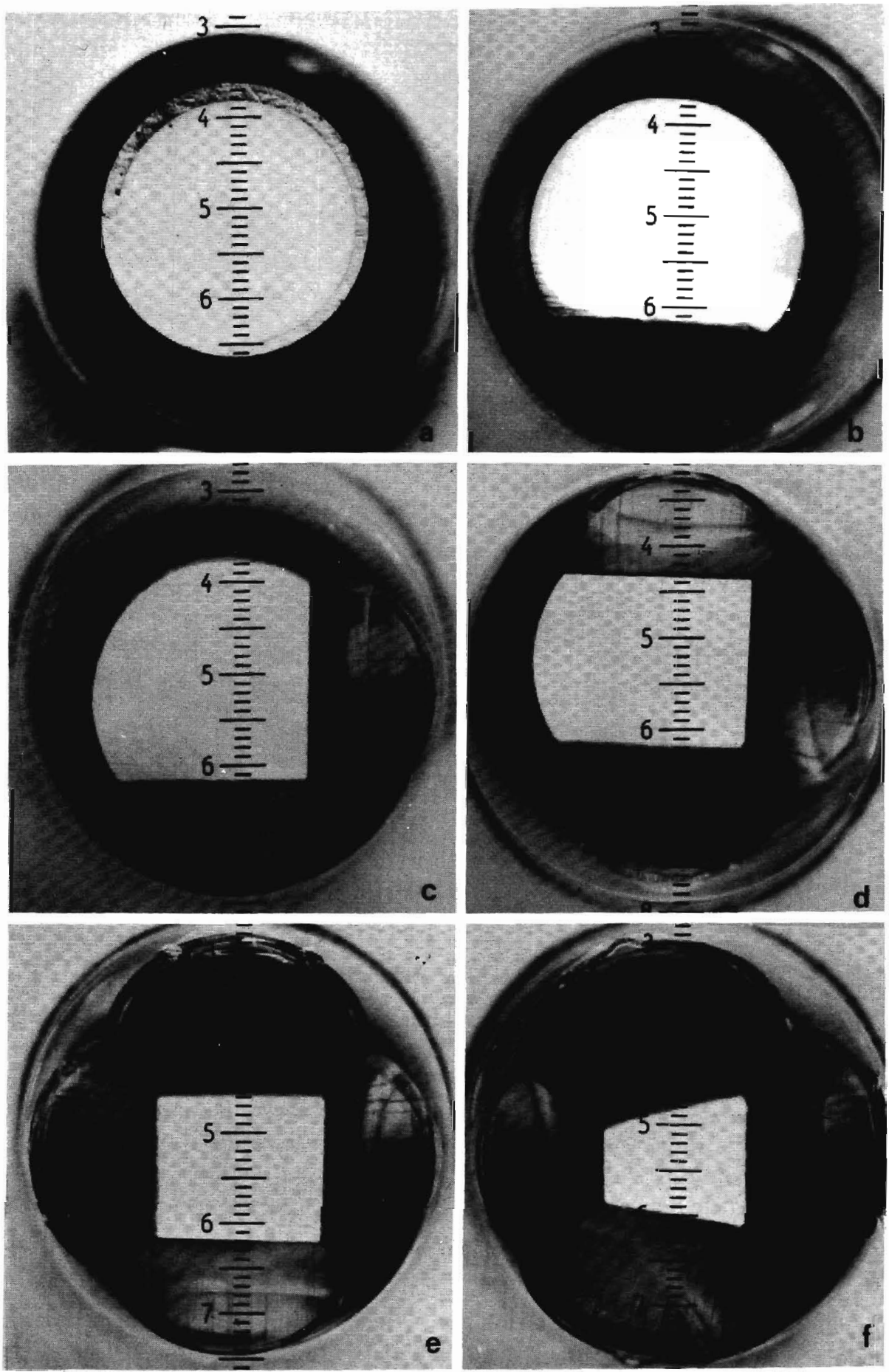

FIG. 3. Steps in process of trimming a specimen block to form either a rectangular (e) ar trapezoidal (f) block face. $\times 10$. 
chuck is then transferred to the trimmer and the block is initially trimmed into a relatively large truncated pyramid with a face about $2 \times 2 \mathrm{~mm}$ to include the total width and height of the embedded specimen (Fig. 3e). The location and orientation of the tissue is not critical for this step. To form the large truncated pyramid (for light microscopy), the block is first centered in the binocular microscope field of view with the horizontal control unit. The knife is then lowered to the flat surface of the block and a numerical note is made of the blade-plastic contact point using the scale of the ocular micrometer (Fig. 3a). This number serves as reference during the trimming process, hence, as a numerical indicator of the initial blade-plastic contact point and therefore the exact position of each consecutive slice made. This number remains constant unless the support arm, the height of the specimen block in the chuck, or the position of the chuck in the holder is adjusted. Beginning at the outer edge of the block, the plastic is progressively cut away by turning one of the adjustment screws of the horizontal control unit $\left(\mathrm{C}_{1}\right.$ or $\mathrm{C}_{2}$, respectively) clockwise and moving the knife up and down. The maximum size of each cut for epoxy resins should be ca. 3 ocular micrometer units (i.e. 3 units, as seen in the microscope) as larger cuts will leave ragged surfaces. The cutting process continues until the blade is within 1-2 ocular micrometer units from the tissue. The horizontal control unit is now rotated clockwise through $90^{\circ}$ and cutting proceeds as described above. By continuing this manner through $180^{\circ}$ and then $270^{\circ}$, the four edges of the face of the block can be systematically cut at right angles to each other (Fig. 3b-e).

The chuck is then returned to the microtome and thick sections $(0.5-2.0 \mu \mathrm{m})$ are cut and examined until an area containing pertinent tissue to be examined with transmission electron microscopy (TEM) is located. The chuck is then remounted in the trimmer and using anatomical or artificial markers, the block face is recut to dimensions suitable for TEM ultramicrotomy. The trimming procedure is summarized photographically in Figure 3a-f.

\section{Acknowledgments}

The authors sincerely thank Mr. R. Kussatz for the manufacture and construction of the trimmer, Mrs. A. Sobotka for preparation of the technical drawing, Miss E. Reupke for technical assistance, and Drs. J. B. Speakman and R. D. Warmbrodt for their critical reading of the manuscript.

\section{REFERENCES}

Boyde, A. 1960. Device for the trimming of blocks for ultramicrotomy. J. Ultrastruct. Res. 3: 398-400. Butler, I. K. 1974. A precision hand trimmer for electron microscope tissue blocks. Stain Technol. 49: $129-132$.

Danon, D. 1961. An instrument to trim plastic specimen blocks for electron microscopy prior to sectioning. J. Biophys. Biochem. Cytol. 9: 726-728.

Gorycki, M. A. 1978. Methods for precisely trimming block faces for ultramicrotomy. Stain Technol. 53: 63-66.

Guglielmotti, V. 1976. Device for manual trimming of tissue blocks for ultramicrotomy. Stain Technol. 5l: $135-138$.

Schneider, H. and Sasaki, P. T. 1976. A blade guide for hand trimming resin blocks for ultramicrotomy. Stain Technol. 51: 283-286.

Sjöstrand, F. S. 1967. Electron Microscopy of Cells and Tissues. Academic Press, New York. Vol. 1, pp. 275277. 